Sādhanā Vol. 38, Part 1, February 2013, pp. 89-99. (C) Indian Academy of Sciences

\title{
Elastic buckling strength of corroded steel plates
}

\author{
AHMAD RAHBAR-RANJI \\ Department of Ocean Engineering, AmirKabir University of Technology, \\ Hafez Avenue, Tehran, 15914, Iran \\ e-mail: rahbar@aut.ac.ir
}

MS received 16 May 2012; revised 21 September 2012; accepted 15 January 2013

\begin{abstract}
Corrosion makes structures more vulnerable to buckling and yielding failures. It is common practice to assume a uniform thickness reduction for general corrosion. To estimate the remaining strength of corroded structures, typically a much higher level of accuracy is required, since the actual corroded structures have irregular surfaces. Elastic buckling of simply supported rectangular corroded plates are studied with one- and both-sided irregular surfaces. Eigenvalue analysis by using finite element method (FEM) is employed for computing Euler stress. The influence of various geometric and corrosion characteristics are investigated and it is found the aspect ratio of the plate, the average thickness diminution, the standard deviation of thickness diminution and the amount of corrosion loss have influence on the reduction of buckling strength of the corroded plates. Buckling strength of one- and both-sided corroded plates are the same. In plates with low value of aspect ratio, reduction of buckling strength is negligible. Reduction of buckling strength is more prominent in plates with higher aspect ratio. Reduction of buckling strength is very sensitive to the amount of corrosion loss; the higher the amount of corrosion loss, the more reduction of buckling strength. Reduction of buckling strength is less sensitive to the standard deviation of thickness diminution.
\end{abstract}

Keywords. Corroded steel plate; Euler critical stress; FEM; irregular surface.

\section{Introduction}

Deterioration of aged structures due to corrosion is a common problem in steel structures. For structural safety assessment of corroded structures, residual strength should be determined as a function of time to plan repairs and replacements. Two main corrosion mechanisms, namely, general corrosion and pitting corrosion are recognized. Pitting is a localized corrosion in the form of deep holes and general corrosion which occurs in the relatively larger areas, is due to coalescence of the pits. 
Many research works are devoted on strength evaluation of corroded structures. Nakai et al (2006) have performed a series of nonlinear finite element analysis (FEA) in plates with pit corrosion subjected to in-plane compressive loads and bending moments. Jiang \& Guedes-Soares (2011) and Huang et al (2010) have studied ultimate strength of pitted plates under biaxial compression by using nonlinear FEA approach. Wang et al (2005) have reported strength reduction of corroded deck plates in 20 years old ships under uniform longitudinal compression.

Significant relevant work has been done in the area of residual strength evaluation of corroded structures. However, none of them have involved the sort of simulated corroded surfaces applied in the current work. Actual thickness distribution of the corroded plate would be a time dependent variable and should be expressed as a function of corrosion degree. Strength analysis of such a plate could yield some acceptance criteria to assist surveyors or designers in repairs and replacement planning. Rahbar-Ranji (2001) has proposed a spectrum for random simulation of geometry of a corroded surface based on the mean and standard deviation of thickness diminution. Rahbar-Ranji (2012a) has used this spectrum to analyse plastic collapse load of one- and both-sided corroded plates with irregular surfaces. He has concluded that one-sided corroded plates have maximum reduction of ultimate plastic load. Rahbar-Ranji (2012b, 2013) has also used this spectrum to study ultimate strength and shear buckling strength of corroded plates with irregular surfaces.

The main aim of the present work is to investigate the buckling strength of simply supported plates with one- and both-sided corroded surfaces. Undulated surfaces are generated based on the power spectrum of corroded surface and Euler stress is calculated by using ANSYS code (version 5.6).

\section{Geometry of corroded surface}

General corrosion develops in large areas and yields an irregular surface with variable thickness. Rahbar-Ranji (2001) has proposed a spectrum for geometry of a corroded surface in the following form:

$$
S(k)=\left\{\begin{array}{cc}
\frac{11.88 \alpha \beta \sigma}{k^{2}} \operatorname{Exp}\left[-\frac{2}{3}\left(\frac{\beta}{2.97 \sigma|k|}\right)^{3}\right] \quad \Delta t_{\mathrm{avr}} \leq 2.97 \sigma \\
\frac{\alpha \beta\left(\Delta t_{\mathrm{avr}}+2.97 \sigma\right)^{2}}{\Delta t_{\mathrm{avr}} k^{2}} \operatorname{Exp}\left[-\frac{2}{3}\left(\frac{\beta}{\Delta t_{\mathrm{avr}}|k|}\right)^{3}\right] \quad \Delta t_{\mathrm{avr}} \geq 2.97 \sigma
\end{array}\right.
$$

where $k$ is the wave number, $\Delta t_{\mathrm{avr}}$ and $\sigma$ are the average and standard deviation of the thickness diminution, respectively, and $\alpha$ and $\beta$ are two fitting constants which depend on the corrosion condition and lie in the following ranges:

$$
\begin{aligned}
& \alpha=0.01-0.15 \\
& \beta=0.02-0.15
\end{aligned}
$$

These two constants characterize corrosion conditions and are defined in such a way that the statistical characteristics of a simulated corroded surface be the same as the target surface.

Equation 1 is derived based on the type I asymptotic distribution rule for calculation of the extreme values of thickness diminution. Maximum thickness diminution is assumed as the extreme largest corrosion depth with cumulative probability of $95 \%$ and minimum thickness 


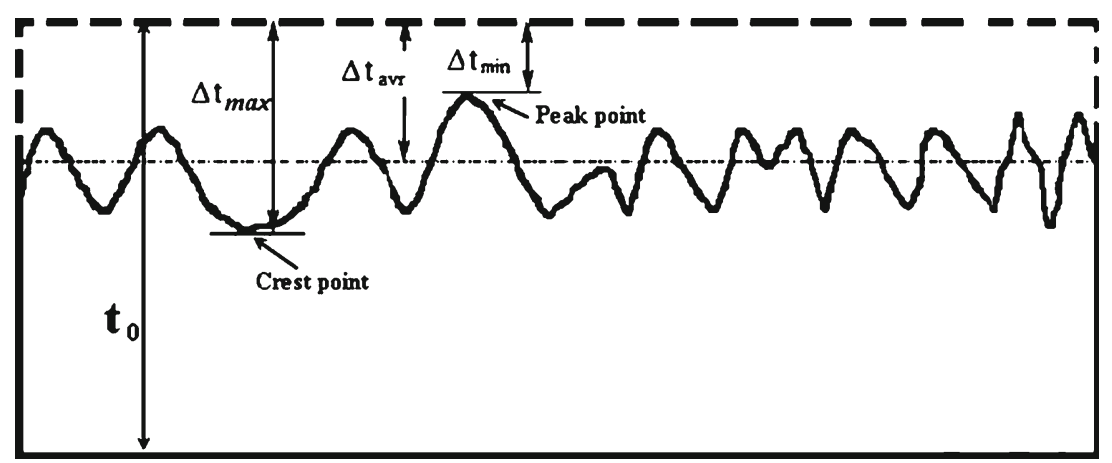

Figure 1. Definition of peak and crest point, $\Delta t_{\mathrm{Max}}, \Delta t_{\mathrm{avr}}$ and $\Delta t_{\min }$ for corroded plate with irregular surface.

diminution is assumed as the smallest corrosion depth with cumulative probability of $5 \%$. According to the type I asymptotic distribution rule, these parameters are calculated as follows

$$
\left\{\begin{array}{c}
\Delta t_{\mathrm{Max}}=\Delta t_{\mathrm{avr}}+2.97 \sigma \\
\Delta t_{\mathrm{min}}=\Delta t_{\mathrm{avr}}-2.97 \sigma
\end{array} .\right.
$$

Minimum corrosion depth is defined as uniform thickness diminution (figure 1).

The average and standard deviation of thickness diminution are two corrosion parameters which are given for any environments. Guo et al (2008) have given equations for calculation of the mean and standard deviation of corrosion wastage in deck plates of single hull tankers as a function of ships age based on measured data. Having the mean and standard deviation of thickness diminution, the spectrum of corroded surface would be known. An isotropic spectrum in two directions is expressed by Equation (1), since the stochastic characteristics of the corroded surfaces in all directions are identical. An equivalent wave number is defined as follows

$$
k_{e q}=\sqrt{k_{1}^{2}+k_{2}^{2}} \text {. }
$$

Three-dimensional geometry of corroded surface is simulated as follows (Goda 1970)

$$
\begin{aligned}
\zeta\left(x_{1}, x_{2}\right)= & \sqrt{2} \sum_{i=1}^{N_{1}} \sum_{j=1}^{N_{2}} \sqrt{2 S\left(k_{1 i}, k_{2 j}\right) \Delta k_{1} \Delta k_{2}} \\
& \times\left[\operatorname{Cos}\left(k_{1 i} x_{1}+k_{2 j} x_{2}+\varphi_{1 i j}\right)+\operatorname{Cos}\left(k_{1 i} x_{1}-k_{2 j} x_{2}+\varphi_{2 i j}\right)\right],
\end{aligned}
$$

where $N_{1}$ and $N_{2}$ are the number of discretization of the spectrum in the $x_{1}$ and $x_{2}$ directions, respectively, $\varphi_{1 i j}$ and $\varphi_{2 i j}$ are random phase angles uniformly distributed between 0 and $2 \pi, \Delta k_{1}$ and $\Delta k_{2}$ are wave number increments in the $x_{1}$ and $x_{2}$ directions, respectively and $k_{1 i}=i \Delta k_{1}$ and $k_{2 j}=j \Delta k_{2}$.

\subsection{One-sided corroded plate}

For one-sided corroded plate all thickness reductions occur at one side of the plate. After generating a corroded surface by using Equation (4), this surface and a flat surface on opposite side are 
placed in such a way that the average and standard deviation of thickness diminution of the simulated corroded plate and initial values be the same. Irregular thickness of a one-sided corroded plate is determined as follows

$$
t\left(x_{1}, x_{2}\right)=t_{0}-\Delta t_{\mathrm{avr}}+\zeta\left(x_{1}, x_{2}\right) .
$$

\subsection{Both-sided corroded plate}

To simulate both-sided corroded plate, two undulated surfaces must be generated and positioned in such a way that the average and standard deviation of the thickness diminution of the simulated corroded plate and initial values be the same. Irregular thickness of a both-sided corroded plate is determined as follows:

$$
t\left(x_{1}, x_{2}\right)=t_{0}-\Delta t_{\mathrm{avr}}+\zeta^{+}\left(x_{1}, x_{2}\right)+\zeta^{-}\left(x_{1}, x_{2}\right),
$$

where $\zeta^{+}$and $\zeta^{-}$are ordinates of upper and lower surfaces, respectively. Some statistical studies are needed to determine how thickness reductions are divided between two opposite surfaces, since corrosion information are limited to thickness reduction rather than surface undulation. Another parameter which could have influence on strength of corroded plate is relative position of the crest points on each surface (figure 1).

In this study, both-sided corroded plates with the same thickness reduction parameters at each side and the crest points at the same position are considered.

\section{Elastic buckling analysis of plates}

Euler stress for buckling of a rectangular plate with four edges simply supported is as follows (Timoshenko \& Gere 1961)

$$
\sigma_{P E}=\left(m \frac{b}{a}+\frac{1}{m} \frac{a}{b}\right)^{2} \frac{\pi^{2} D_{P}}{b^{2} t_{P}}
$$

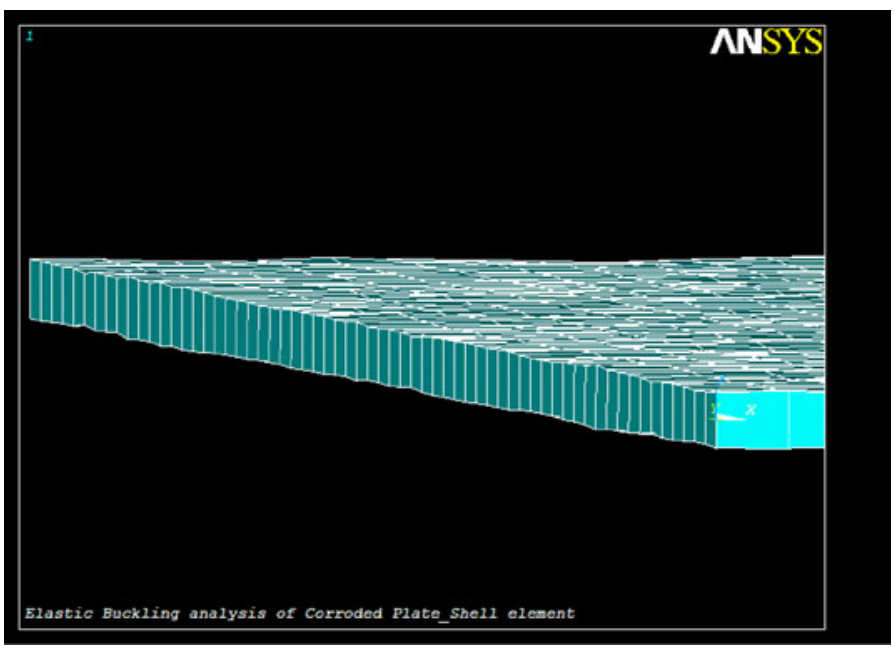

Figure 2. Finite element model of plate with both-sided corroded surfaces (shell elements). 


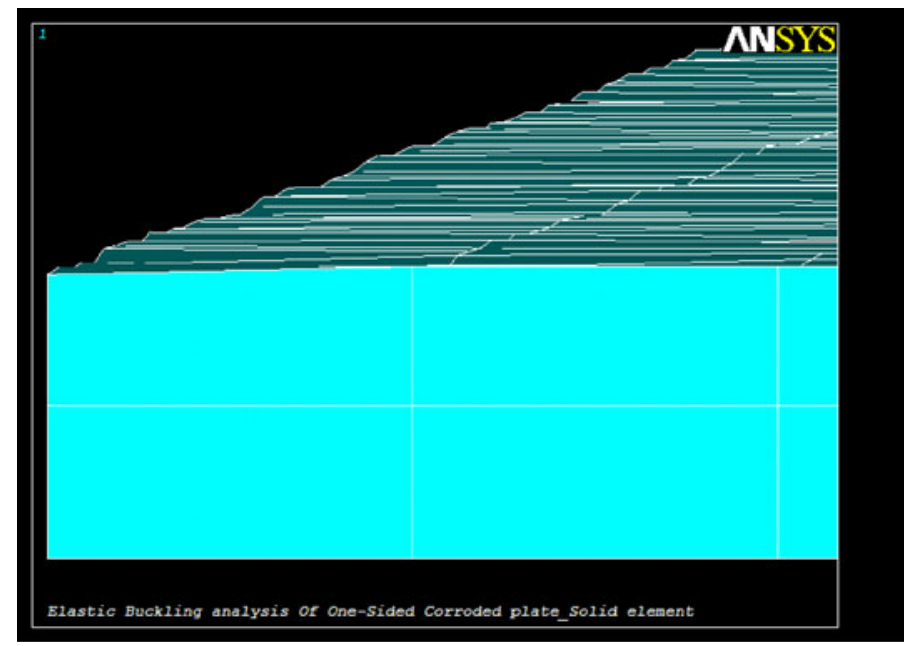

Figure 3. Finite element model of plate with one-sided corroded surfaces (solid elements).

where $D_{P}$ is the plate bending rigidity and is defined as follows:

$$
D_{P}=\frac{E t_{p}^{3}}{12\left(1-v^{2}\right)},
$$

where $t_{p}$ is the thickness of the plate, $a$ is the length of the plate, $b$ is the width of the plate, $E$ is Young's modulus, $v$ is Poisson's ratio, and $m$ is the number of half waves in longitudinal direction and should be determined in such a way that Euler stress be minimum.

Elastic buckling assessment of a corroded plate with irregular surfaces is evaluated only on the basis of numerical analysis with FEM. A computer code in Fortran 90 is developed to generate irregular surfaces based on the mean and standard deviation of thickness diminution. By using shell elements with variable thickness at each node, both-sided corroded plates with the same irregular surfaces at each side are generated. In this case the mid-plane of corroded plates is not dislocated (figure 2). Solid elements should be used to model one-sided corroded plates (figure 3).

\section{Numerical analysis and discussions}

To demonstrate the detrimental effect of corrosion with irregular surfaces on buckling strength of corroded plates, a series of FEM eigenvalue analyses are performed. The computer code ANSYS (version 5.6) has been used for this analysis. One- and both-sided corroded plates are modelled by using SHELL63 and SOLID45 elements, respectively. A uniformly distributed normal stress is applied over one end while holding the other end. Five different corrosion conditions (table 1) are considered and for each case, random irregular surfaces are generated.

Based on studies of Rahbar-Ranji \& Zakeri (2010) corrosion changes the mechanical properties of the steel plate; however, Young's modulus and Poisson's ratio remain unchanged. In this study, material is considered as mild steel with $E=206 \mathrm{GPa}$ and $v=0.3$, width of plate is 
Table 1. Corrosion conditions considered in this work.

\begin{tabular}{lc}
\hline $\begin{array}{l}\text { Mean value of thickness } \\
\text { diminution }(\mathrm{mm})\end{array}$ & $\begin{array}{c}\text { Standard deviation of thickness } \\
\text { diminution }(\mathrm{mm})\end{array}$ \\
\hline 0.5 & 0.1 \\
1.0 & 0.15 \\
1.5 & 0.20 \\
2.0 & 0.25 \\
2.5 & 0.30 \\
\hline
\end{tabular}

assumed to be $600 \mathrm{~mm}$, thickness is $8 \mathrm{~mm}$ and length of plate varies from $600 \mathrm{~mm}$ to $3200 \mathrm{~mm}$. Statistical characteristics of the generated surface for different corrosion conditions together with parameters $\alpha$ and $\beta$ are given in table 2. In this table, CTP is the distance between maximum and minimum points of thickness reduction, or crest-to-peak (CTP) distance which is the maximum height of surface irregularities $\left(\Delta t_{\mathrm{Max}}-\Delta t_{\min }\right)$. As can be seen, parameters $\alpha$ and $\beta$ are chosen in such a way that $\Delta \mathrm{t}_{\mathrm{avr}}$ and $\sigma$ of the simulated surface be near to target values.

Table 2. Statistical characteristics of simulated surfaces.

\begin{tabular}{|c|c|c|c|c|c|c|c|c|c|}
\hline \multicolumn{2}{|c|}{ Target surface } & \multirow{2}{*}{$\begin{array}{c}\text { Plate } \\
\text { dimensions } \\
(\mathrm{mm})\end{array}$} & \multicolumn{7}{|c|}{ Simulated surface } \\
\hline $\begin{array}{l}\Delta \mathrm{t}_{\mathrm{avr}} \\
(\mathrm{mm})\end{array}$ & $\begin{array}{c}\sigma \\
(\mathrm{mm})\end{array}$ & & $\alpha$ & $\beta$ & $\begin{array}{l}\Delta t_{\min } \\
(\mathrm{mm})\end{array}$ & $\begin{array}{l}\Delta t_{\mathrm{avr}} \\
(\mathrm{mm})\end{array}$ & $\begin{array}{l}\Delta t_{\max } \\
(\mathrm{mm})\end{array}$ & $\begin{array}{l}C T P \\
(\mathrm{~mm})\end{array}$ & $\begin{array}{c}\sigma \\
(\mathrm{mm})\end{array}$ \\
\hline \multirow[t]{5}{*}{0.5} & 0.1 & $600 \times 600$ & 0.02 & 0.02 & 0.203 & 0.502 & 0.867 & 0.664 & 0.101 \\
\hline & & $1200 \times 600$ & 0.02 & 0.02 & 0.203 & 0.517 & 0.893 & 0.690 & 0.104 \\
\hline & & $1800 \times 600$ & 0.02 & 0.02 & 0.203 & 0.501 & 0.892 & 0.689 & 0.103 \\
\hline & & $2400 \times 600$ & 0.02 & 0.02 & 0.203 & 0.496 & 0.881 & 0.678 & 0.102 \\
\hline & & $3000 \times 600$ & 0.02 & 0.02 & 0.203 & 0.516 & 0.913 & 0.710 & 0.095 \\
\hline \multirow[t]{5}{*}{1.0} & 0.15 & $600 \times 600$ & 0.03 & 0.02 & 0.554 & 1.071 & 1.681 & 1.127 & 0.150 \\
\hline & & $1200 \times 600$ & 0.02 & 0.03 & 0.554 & 1.050 & 1.687 & 1.133 & 0.152 \\
\hline & & $1800 \times 600$ & 0.022 & 0.024 & 0.554 & 1.056 & 1.605 & 1.050 & 0.150 \\
\hline & & $2400 \times 600$ & 0.02 & 0.027 & 0.554 & 1.015 & 1.621 & 1.067 & 0.151 \\
\hline & & $3000 \times 600$ & 0.022 & 0.027 & 0.554 & 1.033 & 1.591 & 1.036 & 0.154 \\
\hline \multirow[t]{5}{*}{1.5} & 0.20 & $600 \times 600$ & 0.025 & 0.035 & 0.906 & 1.504 & 2.333 & 1.427 & 0.200 \\
\hline & & $1200 \times 600$ & 0.024 & 0.030 & 0.906 & 1.517 & 2.340 & 1.517 & 0.205 \\
\hline & & $1800 \times 600$ & 0.027 & 0.028 & 0.906 & 1.485 & 2.246 & 1.340 & 0.200 \\
\hline & & $2400 \times 600$ & 0.027 & 0.027 & 0.906 & 1.524 & 2.337 & 1.430 & 0.202 \\
\hline & & $3000 \times 600$ & 0.028 & 0.028 & 0.906 & 1.540 & 2.281 & 1.375 & 0.204 \\
\hline \multirow[t]{5}{*}{2.0} & 0.25 & $600 \times 600$ & 0.035 & 0.030 & 1.257 & 2.027 & 3.145 & 1.888 & 0.251 \\
\hline & & $1200 \times 600$ & 0.030 & 0.032 & 1.257 & 2.079 & 3.119 & 1.861 & 0.249 \\
\hline & & $1800 \times 600$ & 0.031 & 0.030 & 1.257 & 2.085 & 3.024 & 1.767 & 0.249 \\
\hline & & $2400 \times 600$ & 0.032 & 0.030 & 1.257 & 2.069 & 3.011 & 1.753 & 0.250 \\
\hline & & $3000 \times 600$ & 0.050 & 0.020 & 1.257 & 2.076 & 3.124 & 1.866 & 0.257 \\
\hline \multirow[t]{5}{*}{2.5} & 0.3 & $600 \times 600$ & 0.040 & 0.030 & 1.609 & 2.505 & 3.601 & 1.992 & 0.301 \\
\hline & & $1200 \times 600$ & 0.039 & 0.030 & 1.609 & 2.529 & 3.844 & 2.235 & 0.298 \\
\hline & & $1800 \times 600$ & 0.038 & 0.030 & 1.609 & 2.581 & 3.784 & 2.175 & 0.303 \\
\hline & & $2400 \times 600$ & 0.040 & 0.030 & 1.609 & 2.585 & 3.867 & 2.258 & 0.301 \\
\hline & & $3000 \times 600$ & 0.040 & 0.030 & 1.609 & 2.570 & 3.692 & 2.080 & 0.309 \\
\hline
\end{tabular}


Euler stress for plates with variable thickness at each node are calculated by using FEM and compared with Euler stress of plates with uniform thickness using Equation (7). A reduction factor is defined as follows

$$
R_{d}=\frac{\left(\sigma_{P E}\right)_{\text {Rough }}}{\left(\sigma_{P E}\right)_{\text {Flush }}},
$$

where $\sigma_{P E}$ is Euler stress for plate buckling. To express the effect of corrosion on the reduction of buckling strength, corrosion loss is introduced as follows

$$
\text { Corrosion loss }=\frac{\text { lost weight }}{\text { Initial weight }} \times 100 \text {. }
$$

Table 3 gives Euler stresses, the amount of corrosion loss and reduction factor for plates with both-sided corroded surfaces and different corrosion conditions.

As can be seen, for plates with aspect ratio less than four and amount of corrosion loss less than 30 percent, the reduction factor is very near to one. This means that for these cases the difference between variable thickness assumption and uniform thickness assumption are negligible. For plates with aspect ratio of five, the reduction factor is near to one when the amount of corrosion

\begin{tabular}{|c|c|c|c|c|c|c|}
\hline \multicolumn{2}{|c|}{ Target surface } & \multirow{2}{*}{$\begin{array}{c}\text { Plate } \\
\text { dimensions } \\
(\mathrm{mm})\end{array}$} & \multirow{2}{*}{$\begin{array}{c}\text { Corrosion } \\
\text { loss ratio } \\
(\%)\end{array}$} & \multicolumn{2}{|c|}{ Euler stress (MPa) } & \multirow[b]{2}{*}{$\begin{array}{l}\text { Reduction } \\
\text { factor }\end{array}$} \\
\hline $\begin{array}{l}\Delta t_{\mathrm{avr}} \\
(\mathrm{mm})\end{array}$ & $\begin{array}{c}\sigma \\
(\mathrm{mm})\end{array}$ & & & $\begin{array}{l}\text { Irregular } \\
\text { thickness }\end{array}$ & $\begin{array}{l}\text { Uniform } \\
\text { thickness }\end{array}$ & \\
\hline \multirow[t]{5}{*}{0.5} & 0.1 & $600 \times 600$ & 6.80 & 115.86 & 115.15 & 1.01 \\
\hline & & $1200 \times 600$ & 6.80 & 114.79 & 114.91 & 1.00 \\
\hline & & $1800 \times 600$ & 6.75 & 115.18 & 115.13 & 1.00 \\
\hline & & $2400 \times 600$ & 6.64 & 117.93 & 115.41 & 1.02 \\
\hline & & $3000 \times 600$ & 6.80 & 115.85 & 115.00 & 1.01 \\
\hline \multirow[t]{5}{*}{1.0} & 0.15 & $600 \times 600$ & 13.26 & 99.34 & 99.61 & 1.00 \\
\hline & & $1200 \times 600$ & 13.83 & 98.10 & 98.29 & 1.00 \\
\hline & & $1800 \times 600$ & 14.00 & 97.92 & 97.90 & 1.00 \\
\hline & & $2400 \times 600$ & 13.41 & 98.99 & 99.28 & 1.00 \\
\hline & & $3000 \times 600$ & 13.06 & 99.39 & 100.07 & 0.99 \\
\hline \multirow[t]{5}{*}{1.5} & 0.20 & $600 \times 600$ & 19.90 & 84.30 & 84.95 & 0.99 \\
\hline & & $1200 \times 600$ & 19.95 & 85.01 & 84.84 & 1.00 \\
\hline & & $1800 \times 600$ & 19.52 & 85.75 & 85.76 & 1.00 \\
\hline & & $2400 \times 600$ & 20.01 & 84.24 & 84.71 & 0.99 \\
\hline & & $3000 \times 600$ & 19.46 & 84.93 & 85.88 & 0.99 \\
\hline \multirow[t]{5}{*}{2.0} & 0.25 & $600 \times 600$ & 26.25 & 71.58 & 72.01 & 0.99 \\
\hline & & $1200 \times 600$ & 26.76 & 71.10 & 71.02 & 1.00 \\
\hline & & $1800 \times 600$ & 26.54 & 71.74 & 71.44 & 1.00 \\
\hline & & $2400 \times 600$ & 26.29 & 71.47 & 71.93 & 0.99 \\
\hline & & $3000 \times 600$ & 26.05 & 68.71 & 72.41 & 0.96 \\
\hline \multirow[t]{5}{*}{2.5} & 0.3 & $600 \times 600$ & 32.91 & 59.95 & 59.60 & 1.01 \\
\hline & & $1200 \times 600$ & 33.53 & 58.74 & 58.52 & 1.00 \\
\hline & & $1800 \times 600$ & 33.23 & 58.71 & 59.03 & 0.99 \\
\hline & & $2400 \times 600$ & 33.49 & 57.42 & 58.58 & 0.98 \\
\hline & & $3000 \times 600$ & 32.43 & 58.70 & 60.44 & 0.97 \\
\hline
\end{tabular}

Table 3. Euler stress for both-sided corroded plates. 
Table 4. Euler stress for one-sided and both-sided corroded plate, corrosion loss 6.60-6.80\% $\left(\Delta t_{\mathrm{avr}}=0.5 \mathrm{~mm}, \sigma=0.1 \mathrm{~mm}\right)$.

\begin{tabular}{lcc}
\hline & \multicolumn{2}{c}{ Euler stress (MPa) } \\
\cline { 2 - 3 } $\begin{array}{l}\text { Plate dimensions } \\
(\mathrm{mm})\end{array}$ & $\begin{array}{c}\text { One-sided corroded plate } \\
\text { (solid elements) }\end{array}$ & $\begin{array}{c}\text { Both-sided corroded plate } \\
\text { (shell elements) }\end{array}$ \\
\hline $600 \times 600$ & 114.94 & 115.86 \\
$1200 \times 600$ & 114.80 & 114.79 \\
$1800 \times 600$ & 115.19 & 115.18 \\
$2400 \times 600$ & 115.05 & 117.93 \\
$3000 \times 600$ & 115.05 & 115.85 \\
\hline
\end{tabular}

loss is less than 20 percent. For higher amount of the corrosion loss, the reduction factor is lower than one.

Table 4 shows reduction factor of buckling strength for one- and both-sided corroded plates with constant corrosion loss.

As can be seen, the reduction of buckling strength for one- and both-sided corroded plates, are very close. Therefore, buckling strength of the corroded plates is independent of how corrosion has occurred at each side of plates.

Figure 4 shows the effect of standard deviation of thickness diminution (roughness of surface) on the reduction of buckling strength of plates with dimensions $3000 \times 600 \mathrm{~mm}$, and average thickness diminution $2.5 \mathrm{~mm}$. As can be seen, the roughness of surface has little effect on the reduction of buckling strength. Generally speaking, by increasing the standard deviation of thickness diminution (roughness of surface), reduction factor is decreased.

Figure 5 shows the relation between reduction factor of buckling strength and the average thickness diminution. In this figure, plate with dimension $3000 \times 600 \mathrm{~mm}$ and standard deviation of thickness diminution $0.3 \mathrm{~mm}$ is considered. As can be seen, the average thickness diminution has influence on reduction factor. However, its influence is not definite and cannot be expressed explicitly. By increasing the average thickness diminution, the reduction factor of buckling strength maybe increased or decreased.

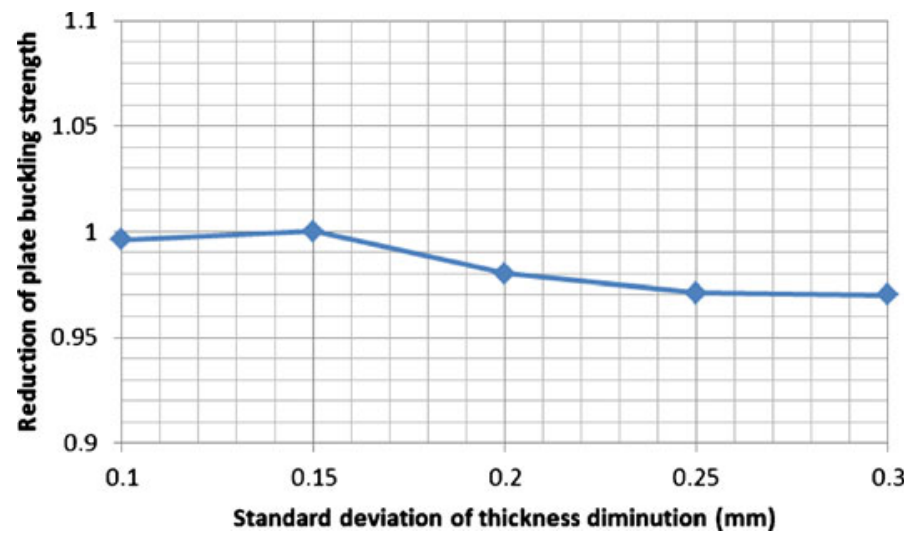

Figure 4. Reduction factor of buckling strength of corroded plate as a function of standard deviation of thickness diminution (plate dimension $3000 \times 600 \mathrm{~mm}$, average thickness diminution $2.50 \mathrm{~mm}$ ). 


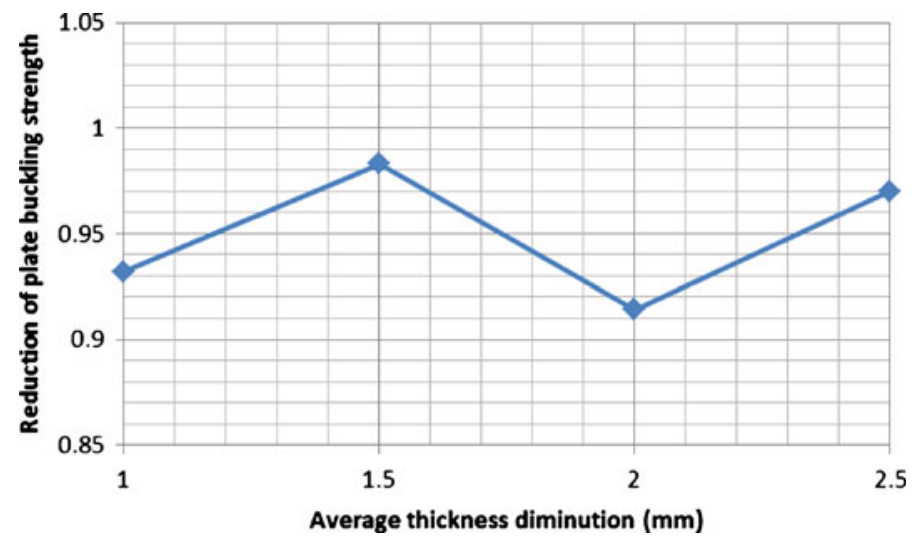

Figure 5. Reduction factor of buckling strength of corroded plate as a function of average thickness diminution (plate dimension $3000 \times 600 \mathrm{~mm}$, standard deviation $0.30 \mathrm{~mm}$ ).

Figure 6 shows the relation between reduction factor of buckling strength and the amount of corrosion loss. Plates with dimensions of $3000 \times 600 \mathrm{~mm}, 2400 \times 600 \mathrm{~mm}$, and $1200 \times 600 \mathrm{~mm}$, and the average thickness diminution $2.0 \mathrm{~mm}$, and standard deviation of thickness diminution $0.25 \mathrm{~mm}$ are considered.

As can be seen, buckling strength of the corroded plates is very sensitive to the amount of corrosion loss and aspect ratio of plates. As concluded before, for plates with lower aspect ratio, say two, the reduction of buckling strength is negligible irrespective of the amount of corrosion loss. For plates with higher aspect ratio, reduction of buckling strength is more prominent. By increasing the amount of corrosion loss, reduction factor decreases. When corrosion loss reaches to 50 percent, the reduction factor is about 0.8 for plate with aspect ratio of five $(3000 \times 600 \mathrm{~mm})$, about 0.9 in plate with aspect ratio of four $(2400 \times 600 \mathrm{~mm})$, and about 0.98 in plate with aspect

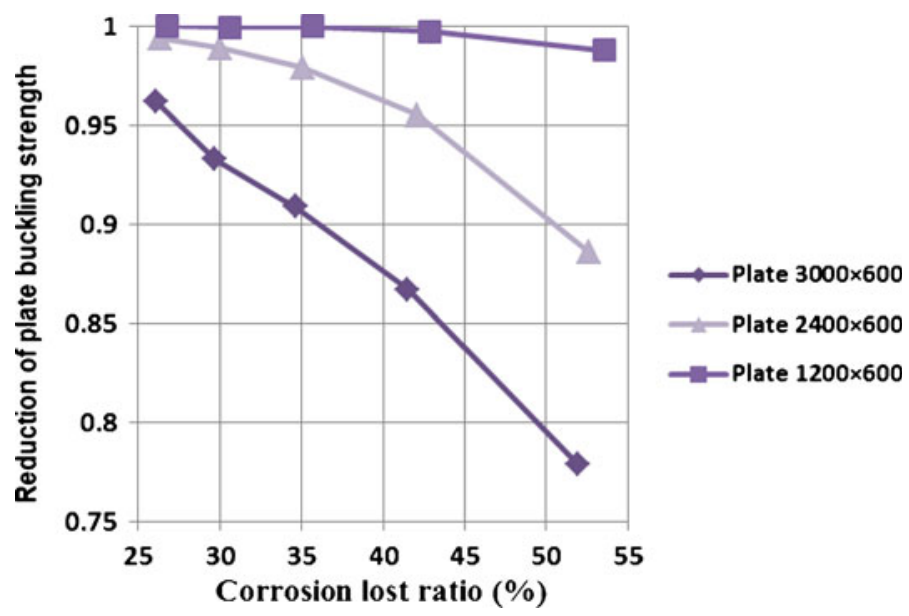

Figure 6. Reduction factor of buckling strength of corroded plate as a function of corrosion loss ratio (average thickness diminution $2.0 \mathrm{~mm}$ and standard deviation $0.25 \mathrm{~mm}$ ). 


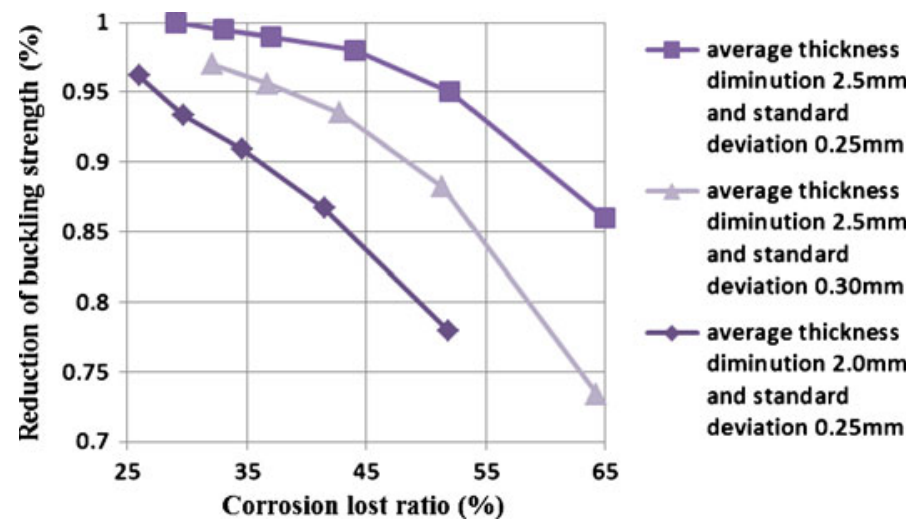

Figure 7. Reduction factor of buckling strength of corroded plate as a function of corrosion loss ratio, plate dimension $3000 \times 600 \mathrm{~mm}$.

ratio of two $(1200 \times 600 \mathrm{~mm})$. Therefore, for thin plate with higher aspect ratio, uniform thickness assumption could lead up to 20 percent overestimation of buckling strength when 50 percent of thickness of plate is reduced due to corrosion.

Figure 7 shows the effect of the amount of corrosion loss on the reduction of buckling strength for different corrosion conditions. In this figure, plate dimension is assumed as $3000 \times 600 \mathrm{~mm}$.

Regardless of corrosion conditions, by increasing the amount of corrosion loss, reduction factor is decreased. Comparing two cases of the average thickness diminution $2.5 \mathrm{~mm}$ and standard deviation $0.25 \mathrm{~mm}$ with the average thickness diminution $2.5 \mathrm{~mm}$ and standard deviation $0.3 \mathrm{~mm}$, it implies that by increasing roughness of surface (standard deviation of thickness diminution), reduction factor can be decreased. Comparing two cases of the average thickness diminution $2.5 \mathrm{~mm}$ and standard deviation $0.25 \mathrm{~mm}$ with the average thickness diminution $2.0 \mathrm{~mm}$ and standard deviation $0.25 \mathrm{~mm}$, it implies that by decreasing the average thickness diminution the reduction factor is decreased.

\section{Conclusions}

There is little study on the strength of corroded plates with irregular surfaces especially as a function of corrosion parameters. Eigenvalue analysis using FEM is employed for Euler stress analysis of corroded plates with one- and both-sided irregular surfaces. It is found that buckling strength of one- and both-sided corroded plates are the same when corrosion loss is constant. Influential parameters are studied and it is found that the amount of corrosion loss, the average thickness diminution, aspect ratio of plate and standard deviation of thickness diminution have influence on reduction of buckling strength. It is found that reduction of buckling strength is very sensitive to the amount of corrosion loss and plate aspect ratio. For plates with aspect ratio less than two, the reduction of buckling strength is negligible irrespective of the amount of corrosion loss. For plates with higher aspect ratio, the reduction of buckling strength is more prominent. Regardless of corrosion conditions, by increasing the amount of corrosion loss, reduction factor is decreased. Reduction of buckling strength is less sensitive to the standard deviation of the thickness diminution. However, by increasing the standard deviation of thickness diminution the reduction of buckling strength is increased. Influence of average thickness diminution on reduction factor of buckling strength is not definite. 


\section{References}

Goda Y 1970 Numerical experiments on wave statistics with spectral simulation. Rep. Port Harbor Res. Inst. 9(3): 3-57

Guo J, Wang G, Ivanov L and Perakis N 2008 Time varying ultimate strength of aging tanker deck plate considering corrosion effect. Mar. Struct. 21: 402-419

Huang Y, Zhang Y, Liu G and Zhang Q 2010 Ultimate strength assessment of hull structural plate with pitting corrosion damnification under biaxial compression. Ocean Eng. 37: 1503-1512

Jiang X and Guedes-Soares C 2011 Ultimate capacity behaviour of pitted steel plates under biaxial compression. Proceedings of the $30^{\text {th }}$ International Conference on Ocean, Offshore and Arctic Engineering (OMAE 2011); Rotterdam, The Netherland. New York, USA: ASME; OMAE2011-49980

Nakai T, Matsushita H and Yamamoto N 2006 Effect of pitting corrosion on the ultimate strength of steel plates subjected to in-plane compression and bending. J. Mar. Sci. Tech. 11(1): 52-64

Rahbar-Ranji A 2001 Stress analysis of a randomly undulated plate due to corrosion in marine structures. Ph.D. Thesis, Yokohama National University, Department of Naval Architecture, Japan

Rahbar-Ranji A 2012a Plastic collapse load of corroded steel plates. Sadhana Academy Proceed. Eng. Sci. 37(3): 341-349

Rahbar-Ranji A 2012b Ultimate strength of corroded steel plates with irregular surfaces under in-plane compression. Ocean Eng. 54: 261-269

Rahbar-Ranji A 2013 Shear buckling strength of corroded steel plates with irregular surfaces. J. Zhejiang University-SCIENCE A (Applied Physics and Eng), doi:10.1631/jzus.A1200163, (in press)

Rahbar-Ranji A and Zakeri A H 2010 Mechanical properties and corrosion resistance of normal strength and high strength steels in chloride solution. J. Naval Arch. Mar. Eng. 7: 93-100

Timoshenko S P and Gere J M 1961 Theory of elastic stability. $2^{\text {nd }}$ ed, Engineering Societies Monograph, NY: McGraw Hill

Wang G, Spencer J and Sun H 2005 Assessment of corrosion risks to aging ships using an experience database. J. Offshore Mech. Arctic. Eng. 127(2): 167-174 